\title{
Rotor Eddy Current Power Loss in Permanent Magnet Synchronous Generators Feeding Uncontrolled Rectifier Loads
}

\author{
A. A. Qazalbash ${ }^{1}$, S. M. Sharkh ${ }^{1}$, N. T. Irenji ${ }^{2}$, R. G. Wills ${ }^{1}$, M. A. Abusara ${ }^{3}$ \\ ${ }^{1}$ Faculty of Engineering and Environment (FEE), University of Southampton, UK. \\ ${ }^{2}$ General Electric $(G E)$ Power Conversion, UK. \\ ${ }^{3}$ Renewable Energy Research Group, University of Exeter, UK.
}

\begin{abstract}
Analytical methods and transient finite element analysis (FEA) with rotating mesh are used to calculate rotor eddy current power loss in a permanent magnet synchronous generator (PMSG) connected to an uncontrolled bridge rectifier. Two winding and rectifier topologies are considered: a 3-phase winding with a 3-phase bridge rectifier and a double 3-phase winding with a 3-phase rectifier each, connected in series. Both magnet flux tooth ripple and stator MMF harmonics are considered in the calculation of rotor loss; the harmonics are added vectorially. Good agreement is observed between analytical and FEA for constant dc link current and constant voltage loads. The machine with double 3-phase windings was found to have considerably lower rotor losses that the machine with one single 3-phase winding.
\end{abstract}

Index Terms_-Permanent Magnet synchronous generator, Rotor loss, Rectifier load

\section{INTRODUCTION}

$\mathrm{R}$ OTOR eddy current power losses can be significant in a permanent magnet synchronous generator (PMSG) connected to an uncontrolled rectifier load [1-4]. In addition to the slot permeance asynchronous harmonics, there are asynchronous flux harmonics caused by switching of the electronic devices, viz. the diodes. These harmonics induce eddy currents in the permanent magnets and other conducting structures on the rotor, i.e., the sleeve and hub, which could result in machine failure due to overheating.

The accuracy of the calculation of rotor losses can be critical when establishing the feasibility of a machine design or making design decisions. Both computational and analytical methods have been developed to estimate these losses. Finite element analysis methods are generally more accurate than analytical method as they incorporate more realistic features such as saturation and end effects [5]. However, even with modern computational resources they can take hours or days before yielding an answer, especially when a 3D solver is used [6].

Analytical methods are quicker and give an insight into the effect of machine design parameters on rotor losses. But due to the simplify assumptions made when developing these methods, the estimated rotor losses could be significantly under- or overestimated.

The commonly used method for calculating rotor losses uses a multilayer machine model, with each harmonic represented by a current sheet placed at the bore of a slotless stator [7-11] - henceforth this model is referred to as the current sheet model or method. In some machines with large gaps, the no-load tooth ripple loss, due to the modulation of magnet flux by the teeth, may be neglected [12-15]. However, in some designs magnet flux tooth ripple loss can be significant [16].

Under certain conditions, namely when the advance angle between back EMF $E$ and current $I$ is zero, eddy current power loss due to magnet flux tooth ripple harmonics and armature reaction flux harmonics can be calculated using superposition of the losses [10], [15, 17-19]. For all other current advance angles that don't equal zero, superposition of the losses leads to inaccurate results [20]. The correct procedure is to add all the harmonics vectorially first and then calculate the loss due to the resultant total harmonics [21],[16].

The calculation of eddy current power loss in PMSG connected to a rectifier load has been of interest in recent years. Rotor losses in PMSG are generally assumed to be due to the armature reaction flux harmonics only and hence the magnet flux tooth ripple component is neglected. A current sheet method is employed to calculate the amplitude of harmonics and their respective power loss [2],[22]. In [2], a combined FEA and analytical method similar to [7] is used to calculate the resultant time and space harmonics. This is done by applying two dimensional Fourier transform on flux density data obtained from magneto-static FEA solutions of the machine at different rotor positions. Yunkai et.al [22] employs the current sheet method developed in [9] to investigate the effect of modular winding configuration on rotor eddy current power loss in PMSG connected to a rectifier load. The method assumes that eddy currents are resistive limited. The rotor power loss results presented show good agreement between analytical and FEA method for PMSG running at low speed. The level of discrepancy between the two methods in terms of rotor power loss calculation will increase at high speed, where the eddy currents are not resistive limited and effect of reaction eddy current may become significant.

In addition to rotor eddy current power losses calculation, methods have also been proposed to reduce these losses. Veen et.al [3], investigate splitting the 3-phase winding into several sections connected to independent rectifiers. The analytical results show that such a winding configuration reduces rotor eddy current power loss in PMSG connected to a rectifier load. The analysis, however, neglects magnet flux tooth ripple harmonics and effect of eddy current reaction.

In this paper, analytical methods and transient finite element analysis (FEA) with rotating mesh are used to calculate rotor eddy current power loss in a permanent magnet synchronous generator (PMSG) connected to an uncontrolled bridge rectifier. Two winding and rectifier topologies are considered: a single 3-phase winding with a 3-phase bridge 
rectifier and a double 3-phase winding with a 3-phase rectifier each, connected in series. Both cases of constant current and constant voltage rectifier dc links are investigated. Both magnet flux tooth ripple and stator MMF harmonics are considered in the analytical calculation of rotor loss. Vector addition is used to calculate the resultant harmonics due to magnet flux tooth ripple and armature reaction flux taking into account the phase angle between each harmonic.

\section{GENERATOR PARAMETERS}

Fig. 1 shows a quarter radial cross-section of the 4 pole, 90,000 rpm permanent magnet synchronous generator (PMSG) under study. The surface mounted permanent magnets are arc-shaped and parallel magnetized. The rotor is made of solid steel for essential strength. The sleeve holding the magnets is non-conducting and non-magnetic. The generator dimensions and properties of materials are shown in Table I.

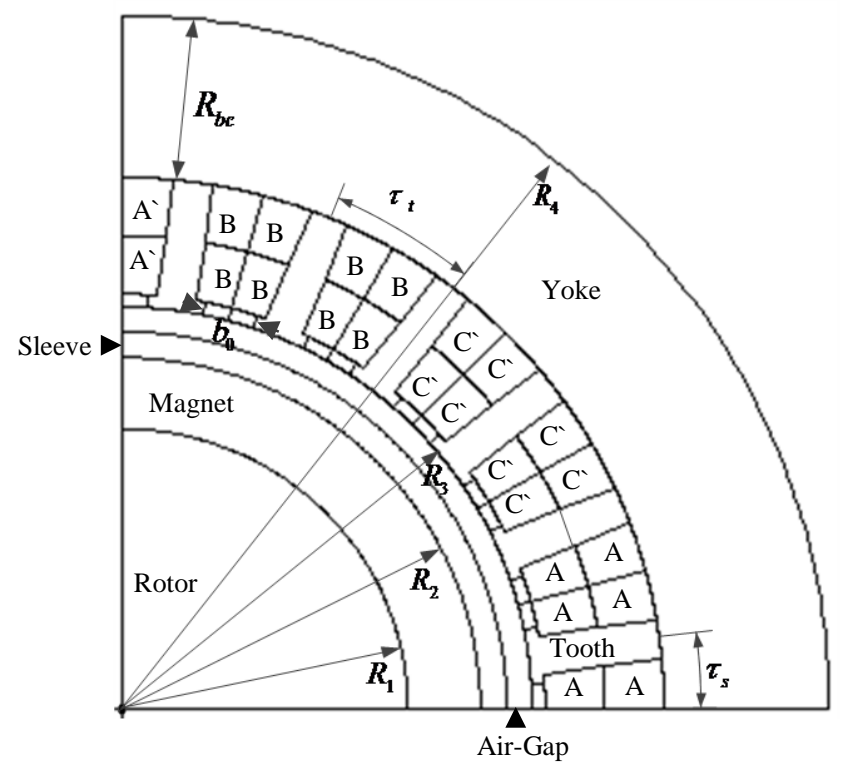

Fig. 1. A quarter model of the permanent magnet synchronous generator understudy.

\section{1) Winding and Rectifier Configurations}

Two winding and rectifier configurations were considered and investigated. In the first configuration, the winding is a 3phase fully pitched double layer lap winding with two slots per pole per phase, feeding one rectifier as shown in Fig. 2.

In the second configuration, the winding is split into two sets of fully pitched double layer, 3-phase, lap windings with 1 slot per pole per phase each. Each set is connected to a 3phase bridge rectifier and the two rectifiers are connected in series as shown in Fig. 3. There is a 30 electrical degrees phase shift between the EMF's of the two sets of three-phase windings as they are displaced in space by 1 slot pitch
TABLE I

Parameters of the machine under study.

\begin{tabular}{|l|l|}
\hline Number of poles, $2 p$ & 4 \\
\hline Number of slots, $Q_{s}$ & 24 \\
\hline Number of winding layers & 2 \\
\hline Number of turns per coil, $N_{c}$ & 1 \\
\hline Number of parallel paths & 1 \\
\hline Coil pitch to pole pitch ratio & 1 \\
\hline pole-arc to pole-pitch ratio, $\alpha_{p}$ & 1 \\
\hline Core length, $L$ & $125 \mathrm{~mm}$ \\
\hline Stator outer radius, $R_{4}$ & $53.5 \mathrm{~mm}$ \\
\hline Stator bore radius, $R_{3}$ & $31 \mathrm{~mm}$ \\
\hline Magnet outer radius, $R_{2}$ & $27.1 \mathrm{~mm}$ \\
\hline Rotor hub radius, $R_{1}$ & $21.6 \mathrm{~mm}$ \\
\hline Magnet thickness, $h_{m}$ & $5.5 \mathrm{~mm}$ \\
\hline Stator back of core, $R_{b c}$ & $13.5 \mathrm{~mm}$ \\
\hline Sleeve thickness, $t_{\text {sleeve }}$ & $2 \mathrm{~mm}$ \\
\hline Tooth pitch, $\tau_{t}$ & $8 \mathrm{~mm}$ \\
\hline Airgap, $g$ & $1.9 \mathrm{~mm}$ \\
\hline Tooth width, $\tau_{w}$ & $3.25 \mathrm{~mm}$ \\
\hline Slot opening, $b_{0}$ & $4 \mathrm{~mm}$ \\
\hline Tooth tip thickness, $t_{\text {tip }}$ & $1 \mathrm{~mm}$ \\
\hline Rotor hub linear, $\mu_{r}$ & 750 \\
\hline Rotor hub conductivity, $\sigma_{r}$ & $6.7 \times 10^{6} \mathrm{~S} / \mathrm{m}$ \\
\hline Magnet conductivity, $\sigma_{m}$ & $0.77 \times 10^{6} \mathrm{~S} / \mathrm{m}$ \\
\hline Magnet material & $\mathrm{NdFeB}$ \\
\hline Magnet Remanence, $B_{r}$ & 1.07 \\
\hline Magnet Coercivity, $H_{c}$ & $781 \mathrm{kA} / \mathrm{m}$ \\
\hline & \\
\hline
\end{tabular}

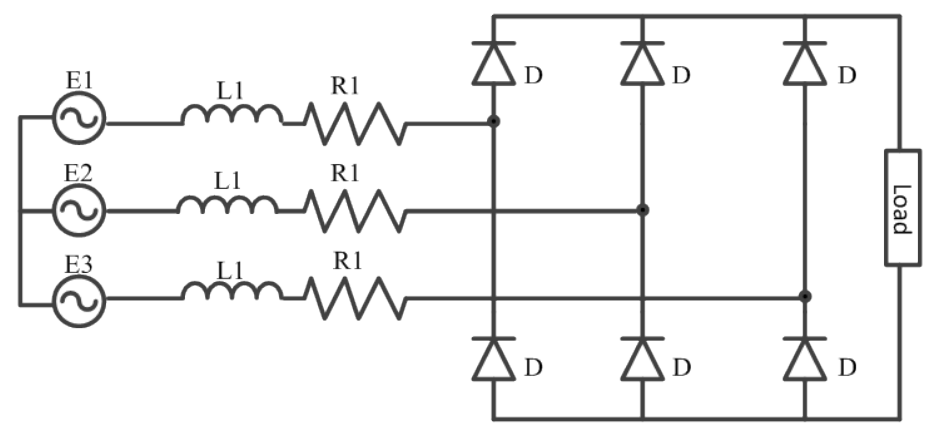

Fig. 2. PMSG with one three phase winding connected to a three phase bridge rectifier.

\section{2) Rectifier Current Waveforms}

In principle the rectifier current could be calculated from a circuit simulation including EMF, resistance and inductance of the winding. For accuracy the winding inductance needs to be frequency dependent and saturation needs to be taken into account. But to enable direct comparison between FEA and analytical calculation, the current produced by the FEA is prescribed in the analytical model. A typical waveform of phase current of a machine connected to two rectifier topologies with a constant dc link current (CC) source is shown in Fig. 4 - the constant current source value was set to 128 A to give an average torque of $7.5 \mathrm{Nm}$ at a speed of $90,000 \mathrm{rpm}$. The waveform for a machine with one rectifier is similar. 


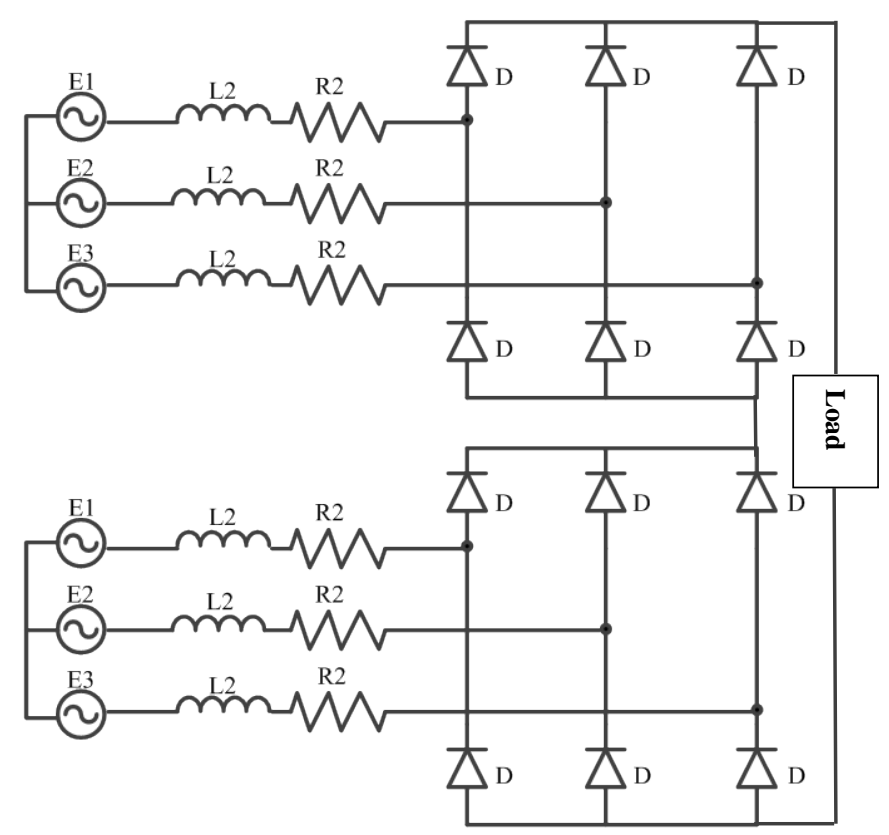

Fig. 3. Equivalent circuit of a PMSG with two sets of three phase windings connected to two rectifiers.

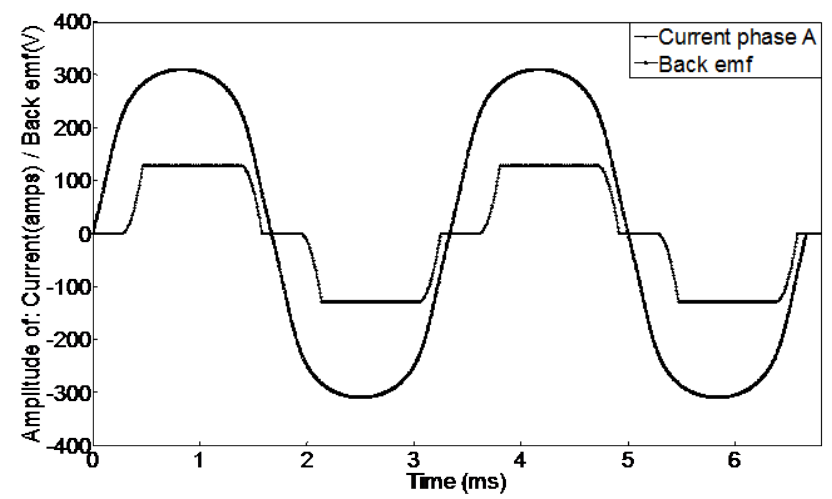

Fig. 4. Phase current and Back emf waveforms of a machine connected to two rectifiers with a constant current (CC) dc link. DC link current is 128A, speed is $90,000 \mathrm{rpm}$ and torque is $7.5 \mathrm{Nm}$.

The phase current and Back emf waveforms of a machine connected to one rectifier with a constant dc link voltage (CV) is shown in Fig. 5 - the dc link voltage was set to be constant at $543 \mathrm{~V}$, the speed was 90,000 rpm and the torque was $6 \mathrm{Nm}$ The waveforms for a machine with two rectifiers with a constant dc link voltage are shown in Fig. 6 - in this case the dc link voltage was $543 \mathrm{~V}$, the torque was $7.5 \mathrm{Nm}$ and the speed was also 90,000 rpm.

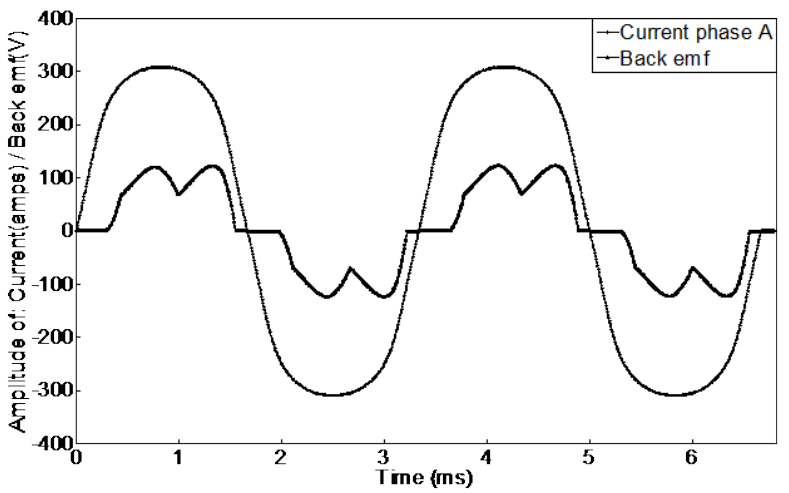

Fig. 5. Phase current and Back emf waveforms of a machine connected to one rectifier with a constant voltage $(\mathrm{CV})$ dc link. DC link voltage $=543 \mathrm{~V}$, speed $=90,000 \mathrm{rpm}$, current $=121 \mathrm{~A}$ and torque $=6 \mathrm{Nm}$.

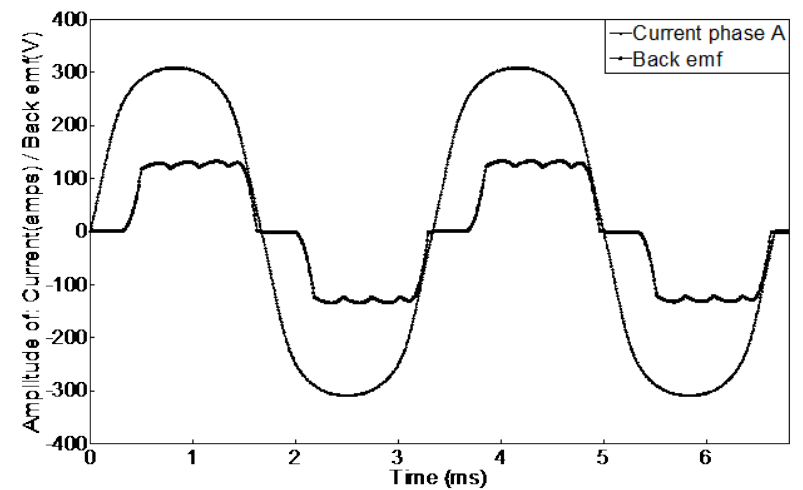

Fig. 6. Phase current and Back emf waveforms of a machine connected to two rectifiers with a constant voltage $(\mathrm{CV})$ dc link. DC link voltage $=543 \mathrm{~V}$, speed $=90,000 \mathrm{rpm}$, current $=121 \mathrm{~A}$ and torque $=7.5 \mathrm{Nm}$.

To add the tooth ripple and armature reaction flux harmonics vectorially, it is important to calculate the phase angle $\psi_{q k}$ between each current harmonic $I$ with respect to the back EMF E. Fourier analysis is performed on the current waveforms shown in Figs. 4, 5, 6 to calculate the amplitude and phase angle of each harmonic in the stator frame. The phase angle $\boldsymbol{\psi}_{q k}$ in stator reference for both rectifier topologies when connected to a constant current dc link current is shown in Table II. The results for the constant voltage dc link case is shown in Table III.

TABLE II

Phase angle $\psi_{q t}$ between Back EMF $E$ and Current $I$ for the constant current dc link case.

\begin{tabular}{|c|c|c|}
\hline Harmonic & $\begin{array}{c}\text { One Rectifier } \\
\text { Topology } \\
\boldsymbol{\psi}_{\text {gt }}\end{array}$ & $\begin{array}{c}\text { Two Rectifier } \\
\text { Topology } \\
\boldsymbol{\psi}_{\text {gt }}\end{array}$ \\
\hline Fundamental & -0.56 & -0.6 \\
\hline $5^{\text {th }}$ & 4.5 & 4.2 \\
\hline $7^{\text {th }}$ & 0.1 & -0.65 \\
\hline $11^{\text {th }}$ & 2.1 & 1.71 \\
\hline $13^{\text {th }}$ & -1.5 & 2.2 \\
\hline $17^{\text {th }}$ & 0.13 & 2 \\
\hline $19^{\text {th }}$ & 1.6 & 2.8 \\
\hline
\end{tabular}


TABLE III

Phase angle $\psi_{q k}$ between Back EMF $E$ and Current $I$ for constant voltage dc link case.

\begin{tabular}{|c|c|c|}
\hline Harmonic & $\begin{array}{c}\text { One Rectifier } \\
\text { Topology } \\
\psi_{q k}(\mathrm{rad})\end{array}$ & $\begin{array}{c}\text { Two Rectifier } \\
\text { Topology } \\
\psi_{q k}(\mathrm{rad})\end{array}$ \\
\hline Fundamental & -0.56 & -0.349 \\
\hline $5^{\text {th }}$ & 1.43 & 2.7 \\
\hline $7^{\text {th }}$ & -0.82 & -0.61 \\
\hline $11^{\text {th }}$ & 0.24 & 2.13 \\
\hline $13^{\text {th }}$ & -2.2 & -0.635 \\
\hline $17^{\text {th }}$ & -1.23 & 1.8 \\
\hline $19^{\text {th }}$ & 2.6 & -1.77 \\
\hline
\end{tabular}

\section{TRAVELLING FLUX HARMONICS}

In this section magnet flux tooth ripple harmonics in the airgap flux density are calculated using the methods in [23], [24] in the rotor reference frame. The armature reaction flux harmonics are calculated using the winding factors derived in [25], [26]. Each travelling harmonic, in the rotor frame, is represented by a current sheet on the surface of a slotless stator as shown in Fig. 7.

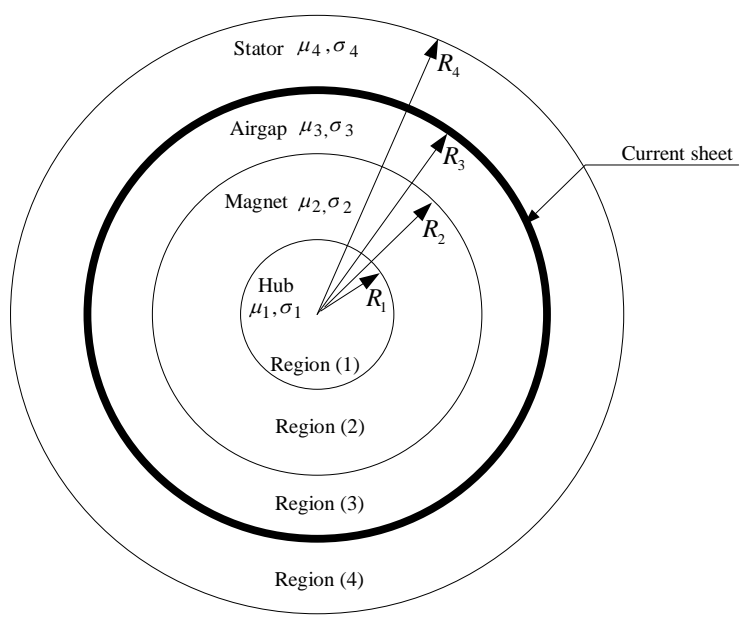

Fig. 7. Cylindrical slotless model of a PM machine in which each MMF harmonic is represented as an equivalent current sheet.

\section{A. Armature Reaction Flux Harmonics}

\section{1) One Rectifier Topology}

In a machine that has a symmetrical three phase stator winding with $p$ pole pairs, and the rotor moving synchronously with the stator fundamental rotating field, the MMF acting across the airgap at any point is equal to the total number of airgap conductors between that point and the nearest peak of the current density wave [26]. The amplitude of the armature reaction flux harmonics with space order $q$ and time order $k, F_{q k}$ can be estimated using:

$$
F_{q k}=\frac{3}{2} \frac{4}{\pi} \frac{N_{p h}}{2 p} \frac{1}{q} K_{w q} \sqrt{2} \hat{I}_{k}
$$

where, $N_{p h}$ is the number of turns per phase, $\hat{I}_{k}$ is the peak amplitude of harmonic current and $K_{w q}$ equals the winding distribution factor [25], since the pitch and skew factors are equal to 1 , :

$$
K_{w q}=\frac{\sin \left(q \cdot \frac{\pi}{2 \cdot m}\right)}{S_{p p} \cdot \sin \left(\frac{q \cdot \pi}{2 \cdot m \cdot S_{p p}}\right)}
$$

where $m$ and $S_{p p}$ are number of phases and slots per pole per phase. The relation between the amplitudes of the armature reaction flux harmonics $F_{q k}$ and its equivalent current sheet $\hat{J}_{q k}$ at the stator bore is given by:

$$
\hat{J}_{q k}=\frac{q p}{R_{3}} \times F_{q k}
$$

The equivalent current sheet for the armature reaction flux harmonic of an arbitrary space order $q$ and time order $k$ has the following distribution:

$$
J_{q k}=\hat{J}_{q k} \cos (q \theta+k \omega t)
$$

where, $J_{q k}$ is the line density of current in $\mathrm{A} / \mathrm{m}, \omega$ is the angular frequency equal to $2 \pi k f, f$ the fundamental frequency.

The airgap flux density due to current sheet, in the absence of eddy currents, can be calculated using the Laplace equation as:

$$
\frac{\partial^{2} A(r, \theta)}{\partial r^{2}}+\frac{1}{r} \frac{\partial A(r, \theta)}{\partial r}+\frac{1}{r^{2}} \frac{\partial^{2} A(r, \theta)}{\partial \theta^{2}}=0
$$

Using the method of separation of variables, the general solution of (4) is given by:

$$
A(r, \theta)=R(r) \cos (q \theta+k \omega t)
$$

Substituting (5) in (4), it can be shown that:

$$
R(r)=C r^{q}+D r^{-q}
$$

where, $C$ and $D$ are constants, to be determined using following two boundary conditions as:

$$
\begin{gathered}
\left.H_{\theta}\right|_{r=R_{1}}=0 \\
\left.H_{\theta}\right|_{r=R_{3}}=-J_{q k}
\end{gathered}
$$

For the permanent magnet machines the airgap flux density $\vec{B}$ and $\vec{H}$ in the airgap are coupled by:

$$
\vec{B}=\mu_{0} \vec{H}
$$

Therefore in terms of vector potential the tangential component of field quantities $\vec{B}$ and $\vec{H}$ can be derived as:

$$
B_{\theta}(r, \theta)=-\frac{\partial A(r, \theta)}{\partial r}
$$




$$
H_{\theta}(r, \theta)=\frac{B_{\theta}(r, \theta)}{\mu_{0}}
$$

Similarly, the radial component of field quantities $\vec{B}$ and $\vec{H}$ are given by:

$$
\begin{aligned}
& B_{r}(r, \theta)=\frac{1}{r} \frac{\partial A(r, \theta)}{\partial \theta} \\
& H_{r}(r, \theta)=\frac{B_{r}(r, \theta)}{\mu_{0}}
\end{aligned}
$$

Hence applying the boundary conditions in (7) and (8), the value of $C$ and $D$ can be derived as:

$$
\begin{aligned}
C & =\frac{D R_{1}^{-q}}{R_{1}^{q}} \\
D & =\frac{J_{q k} R_{3} \mu_{0}}{q\left(R_{1}^{-2 q} R_{3}^{q}-R_{1}^{-q}\right)}
\end{aligned}
$$

The final field solution can be obtained by substituting (14) and (15) into (6). From (6) the value of $R(r)$ is substituted in (5). The value of vector potential from (5) is used in (10) to calculate the radial and tangential airgap flux density as:

$$
\begin{aligned}
& B_{r}(r, \theta)=\frac{J_{q k} R_{3} \mu_{0}\left(R_{1}^{-2 q} r^{q}+r^{-q}\right)}{r\left(R_{1}^{-2 q} R_{3}^{q}-R_{3}^{-q}\right)} \\
& B_{\theta}(r, \theta)=\frac{J_{q k} R_{3} \mu_{0}\left(R_{1}^{-2 q} r^{q}-r^{-q}\right)}{r\left(R_{1}^{-2 q} R_{3}^{q}-R_{3}^{-q}\right)}
\end{aligned}
$$

\section{2) Two Rectifier Topology}

The armature reaction flux harmonics in the case of a PMSG connected to two rectifiers are calculated by defining the MMF distribution for phase a in two winding sets as:

$$
\begin{aligned}
& F_{a_{1}}=F_{1} \cos \left(\frac{\Omega}{\omega}(\omega t)\right)\left(\cos \theta-\frac{1}{3} \cos (3 \theta)\right.\left.+\frac{1}{5} \cos (5 \theta) \ldots . .\right) \\
& F_{a_{2}}=F_{1} \cos \left(\frac{\Omega}{\omega}\left(\omega t-\frac{\pi}{6}\right)\right)\left(\begin{array}{r}
\cos \left(\theta-\frac{\pi}{6}\right) \\
-\frac{1}{3} \cos \left(3\left(\theta-\frac{\pi}{6}\right)\right) \\
+\frac{1}{5} \cos \left(5\left(\theta-\frac{\pi}{6}\right)\right) \ldots . .
\end{array}\right)
\end{aligned}
$$

where $\Omega$ and $F_{1}$ in (18-19) are given by:

$$
\begin{aligned}
\Omega & =k \omega \\
F_{1} & =\frac{4}{\pi} N_{c} \hat{I}_{k}
\end{aligned}
$$

In (20) and (21), $N_{c}$ is the number of turns per coil, respectively. The MMF distribution of phase $b$, represented by $F_{b_{1}}, F_{b_{2}}$ and phase $c$ represented by $F_{c_{1}}, F_{c_{2}}$ will be $120^{\circ}$ and $240^{\circ}$ apart from phase a $F_{a_{1}}, F_{a_{2}}$ respectively. The total sum of three phases MMF $F_{q k}$ is given by:

$$
F_{q k}=F_{a_{1}}+F_{a_{2}}+F_{b_{1}}+F_{b_{2}}+F_{c_{1}}+F_{c_{2}}
$$

The amplitude of armature reaction flux harmonic $F_{q k}$ from (22) is converted to rotor reference frame. Its equivalent current sheet $\hat{J}_{q k}$ at the stator bore is calculated using (2). Equations (3-17) are employed to calculate the amplitude of airgap flux density on the surface of magnet for the two rectifier topology.

\section{B. Magnet flux Tooth Ripple Harmonics}

The approach used to calculate magnet flux tooth ripple harmonics is based on multiplying the flux density of a slotless machine, with a slotting permeance function.

\section{B.1 Slotless Machine Airgap Flux}

The analytical field solution in the airgap of a slotless PM machine with an internal rotor, having parallel magnetized magnets has been presented in [24]. The $B_{s r}$ and $B_{s \theta}$, viz. radial and tangential components of airgap flux distribution produced by the magnet flux only in a slotless PM machine are given by:

$$
\begin{aligned}
& B_{s r}(r, \theta)=\sum_{n=1,3,5, \ldots}^{\infty} K_{B}(n) \cdot f_{B r}(r) \cdot \cos (n p \theta) \\
& B_{s \theta}(r, \theta)=\sum_{n=1,3,5, \ldots}^{\infty} K_{B}(n) \cdot f_{B \theta}(r) \cdot \sin (n p \theta)
\end{aligned}
$$

where, $K_{B}(n), f_{B r}(r)$ and $f_{B \theta}(r)$ for an internal rotor machine with $R_{3}>R_{2}>R_{1}$, can be written as:

$$
\begin{aligned}
& K_{B}(n)=\frac{\mu_{0} M_{n}}{\mu_{r}} \frac{n p}{(n p)^{2}-1} \\
& \left\{\frac{\left(A_{3 n}-1\right)+2\left(\frac{R_{1}}{R_{2}}\right)^{n p+1}-\left(A_{3 n}+1\right)\left(\frac{R_{1}}{R_{2}}\right)^{2 n p}}{\frac{\mu_{r}+1}{\mu_{r}}\left[1-\left(\frac{R_{1}}{R_{3}}\right)^{2 n p}\right]-\frac{\mu_{r}-1}{\mu_{r}}\left[\left(\frac{R_{2}}{R_{3}}\right)^{2 n p}-\left(\frac{R_{1}}{R_{2}}\right)^{2 n p}\right]}\right\} \\
& f_{B r}(r)=\left(\frac{r}{R_{4}}\right)^{n p-1}\left(\frac{R_{2}}{R_{4}}\right)^{n p+1}+\left(\frac{R_{2}}{r}\right)^{n p+1} \\
& f_{B \theta}(r)=-\left(\frac{r}{R_{4}}\right)^{n p-1}\left(\frac{R_{2}}{R_{4}}\right)^{n p+1}+\left(\frac{R_{2}}{r}\right)^{n p+1}
\end{aligned}
$$

The magnetization vector $M_{n}$ is given by:

$$
M_{n}=M_{r n}+n p M_{\theta n}
$$

For parallel magnetized magnets,

$$
\begin{aligned}
& M_{r n}=\frac{B_{r}}{\mu_{0}} \alpha_{p}\left(A_{1 n}+A_{2 n}\right) \\
& M_{\theta n}=\frac{B_{r}}{\mu_{0}} \alpha_{p}\left(A_{1 n}-A_{2 n}\right)
\end{aligned}
$$


For $n p \neq 1$

$$
\begin{aligned}
& A_{1 n}= \frac{\sin [(n p+1)] \alpha_{p} \frac{\pi}{2 p}}{(n p+1) \alpha_{p} \frac{\pi}{2 p}} \\
& A_{2 n}=\frac{\sin \left[(n p-1) \alpha_{p} \frac{\pi}{2 p}\right]}{(n p-1) \alpha_{p} \frac{\pi}{2 p}} \\
& A_{3 n}=\left(n p-\frac{1}{n p}\right) \frac{M_{r n}}{M_{n}}+\frac{1}{n p}
\end{aligned}
$$

where $n, p, \theta, B_{r}, \mu_{r}, \alpha_{p}$ are defined as: an odd integer $(0 \ldots \infty)$; rotor pole pairs; angular position; permanent magnet remanent flux density; relative recoil permeability and pole-arc to polepitch ratio of the magnet, respectively.

\section{B.2 Permeance Function}

To cater for the effect of slotting in a PM machine, the method by Žarko et al.[23], is used to calculate complex permeance function $\lambda_{C P}(r, \theta)$, with both real $\lambda_{a}$ and tangential $\lambda_{b}$ parts,

$$
\lambda_{C P}(r, \theta)=\lambda_{a}+j \lambda_{b}
$$

which is multiplied with radial $B_{s r}(r, \theta)$ and tangential component $B_{s \theta}(r, \theta)$ of the slotless machine airgap flux density to give:

$$
\begin{aligned}
B_{g r}(r, \theta)=\lambda_{a}(r,(\theta-\omega t)) \cdot & B_{s r}(r, \theta)+ \\
& \lambda_{b}(r,(\theta-\omega t)) \cdot B_{s \theta}(r, \theta) \\
B_{g \theta}(r, \theta)=\lambda_{a}(r,(\theta-\omega t)) \cdot & B_{s \theta}(r, \theta)- \\
& \lambda_{b}(r,(\theta-\omega t)) \cdot B_{s r}(r, \theta)
\end{aligned}
$$

The function is calculated using four conformal transformations between the planes to transform the slotted stator geometry into a simple slotless geometry. The airgap flux density is calculated in a plane having slotless machine geometry using the method in [24]. The solution is then transformed back to the original plane having slotted stator to calculate the effect of slotting on airgap flux density. The component of complex relative permeance function, in the rotor frame, can be shown to be given by:

$$
\begin{aligned}
& \lambda_{a}=\lambda_{0}+\sum_{n=1}^{\infty} \lambda_{a n} \cos \left(n Q_{s}(\theta-\omega t)\right) \\
& \lambda_{b}=\sum_{n=1}^{\infty} \lambda_{b n} \sin \left(n Q_{s}(\theta-\omega t)\right)
\end{aligned}
$$

In (29), $\lambda_{0}, \lambda_{a n}$, and $\lambda_{b n}$ are Fourier series coefficients and are calculated from the waveforms, shown in Fig. 8, of the real $\lambda_{a}$ and imaginary $\lambda_{b}$ component of complex relative function using discrete Fourier transform.

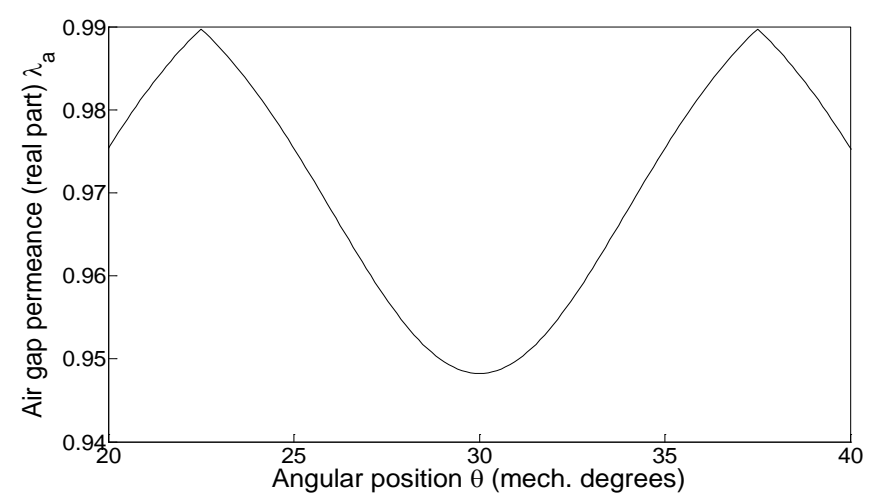

(a)

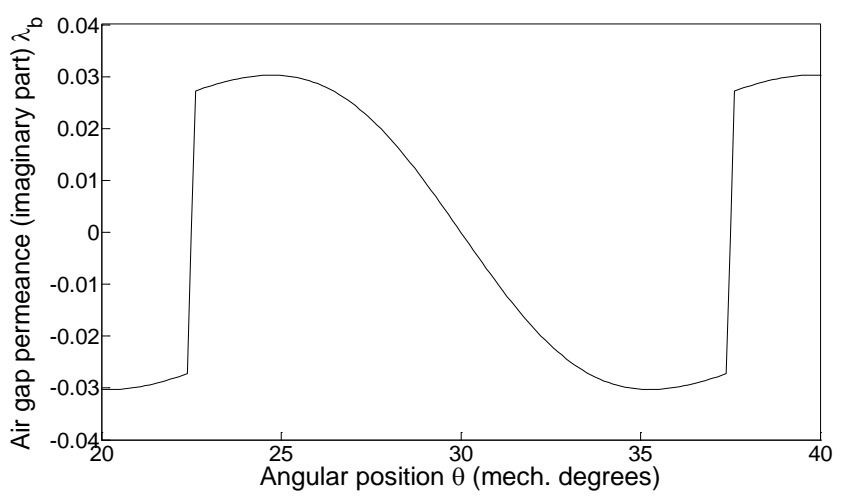

(b)

Fig. 8. Complex relative air-gap permeance per one slot pitch on the surface of the magnet of the machine under study (a) Real component (b) Imaginary component.

\section{Resultant Airgap Flux Harmonics}

The magnet flux tooth ripple and armature reaction flux harmonics of the same order can be added vectorially to obtain resultant harmonics. It is pertinent to mention here that in calculating the resultant harmonic between tooth ripple and armature reaction flux harmonic, angle $\alpha_{q k}$ is defined such that the angle between the rotor and the stator magnetic field axes is always $\left(90-\psi_{q k}\right)$ degrees for the fundamental and other harmonics.

The vector addition of equation (16) and (27) can be performed as:

$$
\begin{aligned}
B_{t}=\sum_{k=0}^{\infty} \sum_{h=1}^{\infty} B_{g r}(r, \theta) \cos (q \theta+k \omega t) \\
+B_{r}(r, \theta) \cos \left(q \theta+k \omega t+\alpha_{q k}\right)
\end{aligned}
$$

Equation (30) can be further simplified as:

$$
\begin{aligned}
B_{t}=\sum_{k=0}^{\infty} \sum_{h=1}^{\infty} B_{g r}(r, \theta) \cos (q \theta+k \omega t) & \\
& +B_{r}(r, \theta)\left(\begin{array}{r}
\cos \left(q \theta+k \omega t+\alpha_{q k}\right) \cos \left(\alpha_{q k}\right) \\
-\sin \left(q \theta+k \omega t+\alpha_{q k}\right) \sin \left(\alpha_{q k}\right)
\end{array}\right)
\end{aligned}
$$


From (31), it can be observed that if the load angle $\psi_{q k}$ between back EMF $E$ and current $I$ is 0 degrees and the angle $\alpha_{q k}$ is at 90 degrees then superposition, viz. direct addition of tooth ripple and stator MMF harmonics can be performed for which (31) becomes:

$$
B_{t}=\sum_{k=0}^{\infty} \sum_{h=1}^{\infty} B_{g r}(r, \theta) \cos (h \theta+k \omega t)+B_{r}(r, \theta)(\cos (h \theta+k \omega t))
$$

For all other values of $\alpha_{q k}$ superposition can't be employed, as the amplitude of harmonics will increase or decrease depending on the angle $\alpha_{q k}$.

\section{ROTOR POWER LOSS CALCULATION}

\section{A. FEA Rotor Eddy Current Power Loss Calculation}

The 2D Maxwell FEA software was used to calculate transient rotor eddy current power loss in PM machine with ring magnets, in order to validate the analytical results. Due to magnetic symmetry it is sufficient to model a quarter portion of the PM machine, covering a full pole pitch, as shown in Fig. 1. The boundary conditions along $x$ and $y$ axis in Fig. 1 are defined to have negative symmetry.

\section{B. Analytical Rotor Eddy Current Power Loss Calculation}

Rotor eddy current power loss due to rotating flux harmonics in time and space is calculated analytically using a current sheet method as shown in Fig. 7. The magnet is assumed to be a conducting region with zero magnetization. This model assumes that a ring magnet is used, and it neglects end effects, which tend to reduce the losses.

The current sheet density of a harmonic of space order $q$ and time order $k$ can be written as [7]:

$$
J_{q k}=\hat{J}_{q k} \cos (q \theta+k \omega t)=\operatorname{Re}\left(\hat{J}_{q k} e^{j q \theta} e^{j k \omega t}\right)
$$

The relationship between the current sheet density and the magnetostatic normal flux density is determined by solving the Laplace equation of the model in Fig. 7 with the conductivities set to zero as discussed in the previous section. The amplitude of the current sheet, $\hat{J}_{q k}$, is set such that it produces the corresponding normal flux density on the surface of the magnet as determined by either (16), (27) or (31).

The Laplacian of the vector potential $A$, assuming no variation in the $z$ direction can be written as:

$$
\nabla^{2} A=\frac{\partial^{2} A(r, \theta, t)}{\partial r^{2}}+\frac{1}{r} \frac{\partial A(r, \theta, t)}{\partial r}+\frac{1}{r^{2}} \frac{\partial^{2} A(r, \theta, t)}{\partial \theta^{2}}
$$

In the air-gap:

$$
\nabla^{2} A=0
$$

In the magnets and steel: $\quad \nabla^{2} A=j k \omega \mu \sigma A$ where $\mu$ and $\sigma$ are the permeability and conductivity of the material. Using the separation of variables method yields the following solution:

$$
A(r, \theta, t)=R(r) e^{i q \theta} e^{j k \omega t}
$$

Substituting (37) in (36), it can be shown that:

$$
R(k r)=C I_{q}(v r)+D K_{q}(v r)
$$

where $v^{2}=j \omega \mu \sigma, I_{q}$ and $K_{q}$ are the modified Bessel functions of the first and second kinds of order $q$. The radial and tangential components of the flux density in different regions, in terms of vector potential are given by:

$$
\begin{aligned}
& B_{r}=\frac{1}{r} \frac{\partial A}{\partial \theta}=\frac{1}{r} j q\left[C I_{q}(v r)+D K_{q}(v r)\right] e^{i q \theta} e^{j k \omega t} \\
& B_{\theta}=-\frac{\partial A}{\partial r}=-v\left[C I_{q}^{\prime}(v r)+D K_{q}^{\prime}(v r)\right] e^{i q \theta} e^{j k \omega t}
\end{aligned}
$$

Equations (39) and (40) are solved to obtain the field solution in each region of the PM machine and constants $C$ and $D$ are determined by applying the boundary conditions. The boundary conditions assume that the radial flux component $B_{r}$ is continuous at all interfaces between regions and the tangential component $H_{\theta}$ is continuous at $r=R_{1}$ and $r=R_{2}$. The only difference will be at the stator bore $R_{3}$ where there is a discontinuity in the tangential field intensity by the amount of current sheet density.

$$
\begin{array}{ll}
B_{r_{1}}=\left.B_{r_{2}}\right|_{r=R_{1}} & H_{\theta_{1}}=\left.H_{\theta_{2}}\right|_{r=R_{1}} \\
B_{r_{2}}=\left.B_{r_{3}}\right|_{r=R_{2}} & H_{\theta_{2}}=\left.H_{\theta_{3}}\right|_{r=R_{2}} \\
B_{r_{3}}=\left.B_{r_{4}}\right|_{r=R_{3}} & H_{\theta_{3}}=\left.H_{\theta_{4}}\right|_{r=R_{3}}+J_{q k} \\
\left.B_{r_{4}}\right|_{r=R_{4}}=0 &
\end{array}
$$

Rotor eddy current power loss can be calculated in each region using the Poynting vector. For a sinusoidal electromagnetic field at steady state, the average power transmitted through a surface is calculated using the Poynting vector as:

$$
P=\frac{1}{2} \operatorname{Re}\left(\mathbf{E} \times \mathbf{H}^{*}\right)
$$

Since we know the solution of Vector potential $A$ from (34), the amplitudes of phasors of $E$ and $H$ can be obtained from the following equations:

$$
\begin{aligned}
& E=-\frac{\partial A}{\partial t}=-j k \omega\left[C I_{q}(v r)+D K_{q}(v r)\right] e^{i q \theta} e^{j k \omega t} \\
& H=-\frac{B_{\theta}}{\mu}=-\frac{1}{\mu} v\left[C I_{q}^{\prime}(v r)+D K_{q}^{\prime}(v r)\right] e^{i q \theta} e^{j k \omega t}
\end{aligned}
$$

Integrating (42) over the magnet surface, the total power transmitted from the airgap to the magnet region, designated by $P_{2}$ and power transmitted to the hub by $P_{1}$ can be calculated in terms of field quantities as: 


$$
\begin{aligned}
& P_{2}=\frac{1}{2} \operatorname{Re}\left\{E_{z_{2}}\left(R_{2}\right) \times H_{\theta_{2}}^{*}\left(R_{2}\right)\right\} S_{2} \\
& P_{1}=\frac{1}{2} \operatorname{Re}\left\{E_{z_{1}}\left(R_{1}\right) \times H_{\theta_{1}}^{*}\left(R_{1}\right)\right\} S_{1}
\end{aligned}
$$

where $S_{2}$ and $S_{1}$ are the surface areas over the magnet and hub surfaces, respectively. The power loss in the magnet region $P_{m}$ and the power loss in the hub region by $P_{h}$ then can be calculated as:

$$
\begin{gathered}
P_{m}=P_{2}-P_{1} \\
P_{h}=P_{1}
\end{gathered}
$$

\section{RESULTS AND DISCUSSION}

\section{A. No-load Magnet Flux Tooth Ripple Harmonics and their Corresponding Rotor Power Loss}

The amplitude of each tooth ripple harmonic and its corresponding rotor eddy current power loss are presented in the Table IV. Rotor eddy current power loss is calculated for harmonics with significant amplitudes. An empty cell in Table IV below indicates that power loss $<0.5 \mathrm{~W}$ and is therefore neglected; a negative sign means that the harmonics are backward rotating and a positive one means that they are forward rotating; and the fundamental frequency is $f_{1}=3000$ $\mathrm{Hz}$ - this applies to all the remaining Tables.

\begin{tabular}{|c|c|c|}
\hline \multirow[b]{2}{*}{ Space order $q$} & \multicolumn{2}{|c|}{ Time order $k$} \\
\hline & 12 & 24 \\
\hline 11 & $0.0047^{-}(8)$ & \\
\hline 13 & $0.0104^{-}(24)$ & \\
\hline 15 & $0.0032^{-}(1.5)$ & \\
\hline 17 & $0.0018-(0.5)$ & \\
\hline 23 & & $0.000318^{-}(<0.5)$ \\
\hline 25 & & $0.0017^{-}(0.5)$ \\
\hline $\begin{array}{l}\text { Power loss (Ar } \\
\text { Power loss (FE }\end{array}$ & $\begin{array}{l}\text { tical) } \\
\text { ransient Solt }\end{array}$ & $\begin{array}{l}\approx 34 \mathrm{~W} \\
\approx 24 \mathrm{~W}\end{array}$ \\
\hline
\end{tabular}

TABLE IV

Magnet flux tooth ripple flux density harmonic amplitudes in Tesla with corresponding power loss in Watts shown in brackets.

\section{B. Flux Harmonics and Corresponding Rotor Power Loss in} Machines Connected to Rectifiers with a Constant Current dc Link

For a PMSG running at 90,000rpm, connected to one rectifier topology feeding a constant current load of 128 A amps, the resultant harmonics between tooth ripple and armature reaction flux harmonics with same space and time order are presented in Table VI. The harmonics and their respective power loss in the two rectifier case with a constant current load of 128 amps are shown in Table VII. Depending on slot / pole combination the harmonics in case of PMSG connected to two rectifier topology cancels out resulting in low power loss.
TABLE VI

Flux density harmonic amplitudes in Tesla with corresponding rotor power loss in Watts shown in brackets for PMSG connected to one rectifier supplying constant current dc load of $128 \mathrm{~A}$.

\begin{tabular}{|c|l|l|l|}
\hline \multirow{2}{*}{ Space order $q$} & \multicolumn{3}{|c|}{ Time order $k$} \\
\cline { 2 - 4 } & \multicolumn{1}{|c|}{6} & \multicolumn{1}{|c|}{12} & 18 \\
\hline 1 & $0.0114^{-}(110)$ & $0.0038^{-}(18)$ & $0.00167^{-}(2)$ \\
& $0.0088^{+}(66)$ & $0.0023^{+}(7)$ & \\
\hline 5 & $0.0031^{-}(8)$ & $0.00045^{-}(1)$ & \\
\hline 7 & $0.0018^{-}(1)$ & & \\
\hline 11 & & $0.004^{-}(6)$ & \\
\hline 13 & & $0.011^{-}(27)$ & \\
\hline 17 & & & \\
\hline 19 & & & \\
\hline \multicolumn{4}{|l|}{ Total Power loss (Analytical) } \\
Power loss (FEA Transient Solution) $\approx 240 \mathrm{~W}$ \\
\hline
\end{tabular}

TABLE VII

Flux density harmonic amplitudes in Tesla with corresponding rotor power loss in Watts shown in brackets for PMSG connected to two rectifiers supplying constant current dc load of $128 \mathrm{~A}$.

\begin{tabular}{|c|l|c|}
\hline \multirow{2}{*}{ Space order $q$} & \multicolumn{2}{|c|}{ Time order $k$} \\
\cline { 2 - 3 } & \multicolumn{1}{|c|}{12} & 24 \\
\hline 1 & $0.004^{-}(20)$ & \\
& $0.003^{+}(11)$ & \\
\hline 5 & $0.002^{-}(10)$ & \\
\hline 7 & $0.0013^{-}(2)$ & \\
\hline 11 & $0.0038^{-}(5)$ & $0.00007^{-}(<0.5)$ \\
\hline 13 & $0.011^{-}(27)$ & $0.00005^{-}(<0.5)$ \\
\hline \multicolumn{3}{|l|}{ Total Power loss (Analytical) $\approx 75 \mathrm{~W}$} \\
Power loss (FEA Transient) $\approx 70 \mathrm{~W}$ \\
\hline
\end{tabular}

Fig. 9 and Fig. 10 present a comparison of rotor eddy current power loss calculated using analytical and FEA methods, for both rectifier topologies. In Fig. 9, the PMSG is running at constant speed of 90,000 rpm and connected to various constant current loads. In Fig. 10, PMSG is connected to a constant current load of 128 amps and running at different speeds

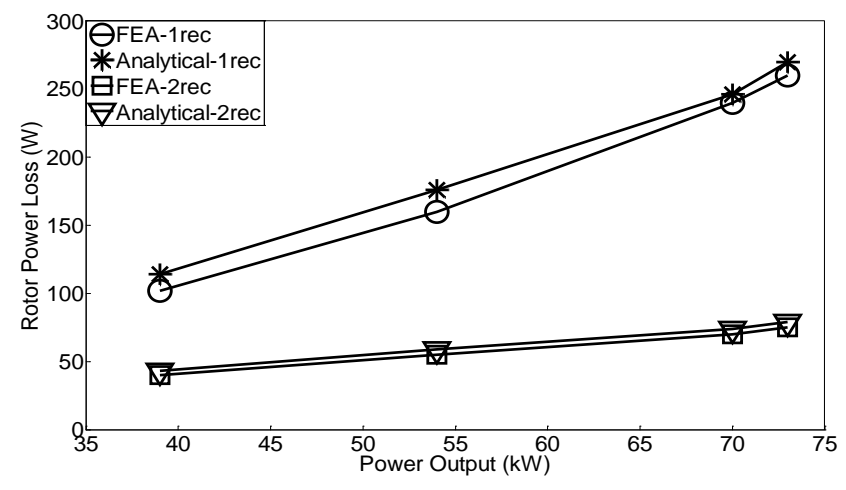

Fig. 9. Rotor power loss vs. Power at 90,000 rpm. Constant current dc link. 


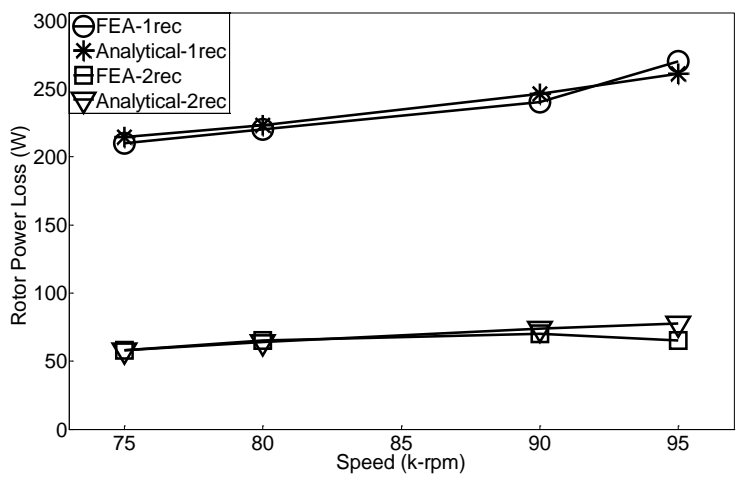

Fig. 10. Rotor power loss vs. speed when supplying a constant current dc link.

C. Flux Harmonics and Corresponding Rotor Power Loss in Machines Connected to Rectifiers with Constant Voltage dc Link

For the case of a PMSG running at 90,000 rpm and connected to one rectifier with a constant dc link voltage of $543 \mathrm{~V}$ supplying a current of $121 \mathrm{amps}$, the resultant harmonics and corresponding losses are presented in Tables VIII. The harmonics and their respective power loss in the case of a PMSG connected to two rectifiers also with a constant dc link voltage of 543V supplying a current of 121 amps is shown in Table IX. The rotor power loss in the two rectifier topology is about $25 \%$ of that of the one rectifier configuration due to the cancellation of the $6^{\text {th }}$ time order mmf harmonics.

TABLE VIII

Flux density harmonic amplitudes in Tesla with corresponding rotor power loss in Watts shown in brackets for PMSG connected to one rectifier supplying constant voltage dc load of $121 \mathrm{~A}, 543 \mathrm{~V}$.

\begin{tabular}{|c|l|l|l|}
\hline \multirow{2}{*}{ Space order $q$} & \multicolumn{3}{|c|}{ Time order $k$} \\
\cline { 2 - 4 } & \multicolumn{1}{|c|}{6} & \multicolumn{1}{|c|}{12} & 18 \\
\hline 1 & $0.0145^{-}(178)$ & $0.0034^{-}(14.5)$ & $0.0018^{-}(1.5)$ \\
& $0.006^{+}(30)$ & $0.0025^{+}(7.5)$ & $0.00145^{+}(1)$ \\
\hline 5 & $0.0029^{-}(7)$ & $0.000602(0.8)$ & \\
\hline 7 & $0.0016^{-}(1)$ & $0.0008(0.7)$ & \\
\hline 11 & & $0.004^{-}(6)$ & \\
\hline 13 & & $0.011^{-}(27)$ & $(<0.5)$ \\
\hline 17 & & & $(<0.5)$ \\
\hline 19 & & & \\
\hline $\begin{array}{l}\text { Total Power loss (Analytical) } \\
\text { Power loss (FEA Transient) }\end{array}$ & $\approx 282 \mathrm{~W}$ \\
\hline
\end{tabular}

TABLE IX

Flux density harmonic amplitudes in Tesla with corresponding rotor power loss in Watts shown in brackets for PMSG connected to two rectifiers supplying constant voltage dc load of $121 \mathrm{~A}, 543 \mathrm{~V}$.

\begin{tabular}{|c|l|c|}
\hline \multirow{2}{*}{ Space order $q$} & \multicolumn{2}{|c|}{ Time order $k$} \\
\cline { 2 - 3 } & 12 & 24 \\
\hline 1 & $0.004^{-}(20)$ & \\
& $0.003^{+}(12)$ & \\
\hline 5 & $0.0016^{-}(6)$ & \\
\hline 7 & $0.0014^{-}(2)$ & \\
\hline 11 & $0.0038^{-}(5)$ & $(<0.5)$ \\
\hline 13 & $0.0112^{-}(28)$ & $(<0.5)$ \\
\hline \multicolumn{3}{|c|}{ Total Power loss (Analytical) $\approx 72 \mathrm{~W}$} \\
Power loss (FEA Transient) $\approx 78 \mathrm{~W}$ \\
\hline
\end{tabular}

Rotor eddy current power loss in a PMSG connected two rectifier topologies for different currents and speeds was calculated using both the analytical and FEA methods as shown in Figs. 11 and 12 . Good agreement is observed between the analytical and FEA results. Again the two rectifier machine has significantly lower rotor losses due to the cancellation of some harmonics.

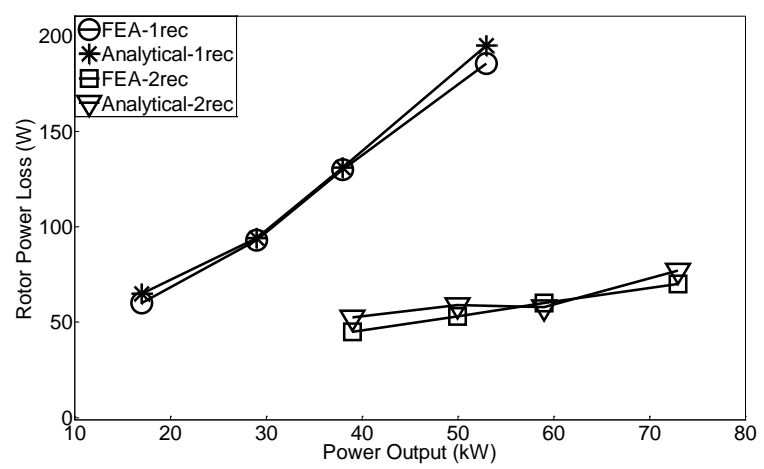

Fig. 11. Rotor power loss vs. Power at 90,000 rpm. Constant voltage dc link.

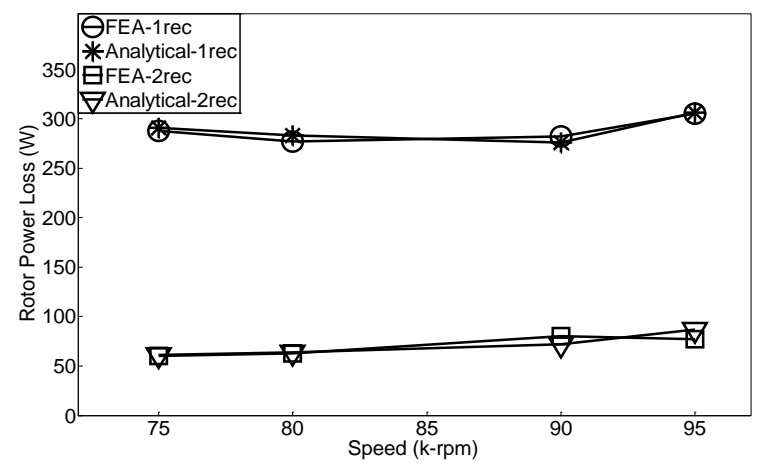

Fig. 12. Rotor power loss vs. speed when supplying a constant voltage dc link.

In general good agreement is observed between the analytical and FEA results. It is worth noting that the machine understudy has negligible saturation. If however, the tooth tip thickness is halved to $0.5 \mathrm{~mm}$, which increases the level of saturation significantly, then the rotor losses in the constant current, one rectifier case, for example, will increase from 240W to 286 Was saturation of the tooth tip virtually increases the slot opening and the amplitude of asynchronous harmonics.

\section{ROTOR LOSSES ARE DIFFICULT TO MEASURE DIRECTLY AS}

THEY ARE SMALL IN COMPARISON TO THE REST OF THE LOSSES

AND TO THAT RATINGS OF THE MACHINE. IN THE MACHINE

UNDERSTUDY, THE COPPER LOSSES ARE ABOUT $270 \mathrm{~W}$ AND THE

CORE LOSSES ARE ABOUT 620 W (0.175 MM LAMINATIONS).

THE WINDAGE LOSSES ARE ESTIMATED TO BE ABOUT $1200 \mathrm{~W}$

AND THE BEARING LOSSES ARE ABOUT $1 \mathrm{KW}$. ON THE OTHER 
HAND THE ROTOR LOSS ON FULL LOAD IN THE DOUBLE

RECTIFIER MACHINE IS ONLY 70W, AND IN THE SINGLE

RECTIFIER MACHINE IS ABOUT 280 W. SOME OF THE ABOVE

LOSSES CAN BE MEASURED WITH A GOOD DEGREE OF

ACCURACY. FOR EXAMPLE, BEARING, STATOR AND WINDAGE

LOSSES CAN BE MEASURED BY MEASURING THE HEAT REMOVED

BY THE COOLING FLUIDS FROM THE KNOWLEDGE OF THE FLOW

RATE AND TEMPERATURE RISE OF THE FLUID. TEMPERATURE

CAN ALSO BE MEASURED AT SEVERAL POINTS IN THE STATOR,

COOLING JACKET AND BEARINGS. MAGNET TEMPERATURE CAN

BE ESTIMATED FROM THE DECREASE OF THE NO-LOAD EMF AND

KNOWN MAGNET REMANENCE TEMPERATURE COEFFICIENT.

THESE MEASUREMENTS COULD BE USED TO INDIRECTLY

ESTIMATE ROTOR LOSSES. MEASUREMENTS ON A MACHINE

SIMILAR TO THE ONE REPORTED IN THIS PAPER CONFIRM THAT

IT HAS A SIGNIFICANTLY LOWER ROTOR TEMPERATURE WHEN

USING A 12 PULSE RECTIFIERS THAN WHEN A 6 PULSE RECTIFIER

IS USED, WHICH VALIDATES THE THEORETICAL CALCULATIONS.

\section{CONCLUSIONS}

Rotor eddy current losses in a PM synchronous generator feeding into an uncontrolled rectifier can be reduced significantly by splitting the three-phase winding into two sections, with a 30 degrees phase shift between their emfs, and each winding connected to its own rectifier. The rectifiers could be connected in series or in parallel. Due to the 30 phase shift between the two sets of windings, some of the stator mmf harmonics and their corresponding rotor losses will be eliminated. This double winding, 12 pulse configuration also has the additional benefit of reducing the dc link voltage ripple.

Good agreement has been observed between the rotor loss analytical calculation method and 2D FEA. But it is essential that the armature and magnet flux harmonics are added vectorially to calculate the resultant travelling flux harmonics and their corresponding losses. The losses due to armature and magnet flux harmonics should not be calculated independently and then added together.

\section{REFERENCES}

[1]

V. V. Vadher, I. R. Smith, and B. A. Fanthome, "Simulation of Permanent Magnet Generator/Rectifier Combination," IEEE Transactions on Aerospace and Electronic Systems, vol. AES-22, no. 1, pp. 64-70, 1986.

[2] H.-W. C. Seok-Myeong Jang, and Yeaon-Ho Jeong, "Influence on the rectifier of rotor losses in highspeed permanent magnet synchronous alternator," Journal of Applied Physics, vol. 99, no. 8, p. 3, 2006. J. L. F. Van der Veen, L. J. J. Offringa, and A. J. A. Vandenput, "Minimising rotor losses in high-speed high-power permanent magnet synchronous generators with rectifier load," IEE Proceedings Electric Power Applications, IEE Proceedings vol. 144, no. 5, pp. 331-337, 1997.

A. K. Nagarkatti, O. A. Mohammed, and N. A. Demerdash, "Special Losses in Rotors of Electronically Commutated Brushless DC Motors Induced by Non-Uniformly Rotating Armature MMFS," IEEE Power Engineering Review, vol. PER-2, no. 12, pp. 33-33, 1982.

[5] K. Yamazaki, Y. Fukushima, and M. Sato, "Loss Analysis of Permanent Magnet Motors with Concentrated Windings - Variation of Magnet Eddy Current Loss Due to Stator and Rotor Shapes," in IEEE Industry Applications Society Annual Meeting, IAS '08., pp. 1-8, 2008.

[6] S. M. Sharkh, A. A. Qazalbash, N. T. Irenji, and R.G.Wills, "Effect of Slot Configuration and Airgap and Magnet thicknesses on Rotor Electromagnetic Loss in Surface PM Synchronous Machines," ICEMS, 2011.

[7] N. T. Irenji, "Calculation of electromagnetic rotor losses in high speed permanent magnet machines," PhD Thesis University of Southampton,1998.

[8] R. L. Stoll and J. K. Sykulski, "Modelling Tooth Ripple Losses In The Solid Pole Faces Of Synchronous Machines," COMPEL-The International Journal for Computation and Mathematics in Electrical and Electronic Engineering, vol. 11, no. 1, pp. 105-108, 1992.

[9] K. Atallah, D. Howe, P. H. Mellor, and D. A. Stone, "Rotor loss in permanent-magnet brushless AC machines," IEEE Transactions on Industry Applications, vol. 36, no. 6, pp. 1612-1618, 2000.

[10] D. Ishak, Z. Q. Zhu, and D. Howe, "Eddy-current loss in the rotor magnets of permanent-magnet brushless machines having a fractional number of slots per pole," IEEE Transactions on Magnetics, vol. 41, no. 9, pp. 2462-2469, 2005.

[11] W. Jiabin, K. Atallah, R. Chin, W. M. Arshad, and H. Lendenmann, "Rotor Eddy-Current Loss in Permanent-Magnet Brushless AC Machines," IEEE Transactions on Magnetics, vol. 46, no. 7, pp. 27012707, 2010.

[12] R. Nuscheler, "Two-dimensional analytical model for eddy-current loss calculation in the magnets and solid 
rotor yokes of permanent magnet synchronous machines," 18th International Conference on Electrical Machines, pp. 1-6, 2008.

[13] Z. Q. Zhu, K. Ng, N. Schofield, and D. Howe, "Improved analytical modelling of rotor eddy current loss in brushless machines equipped with surfacemounted permanent magnets," IEE Proceedings Electric Power Applications, vol. 151, no. 6, pp. 641650, 2004.

[14] L. J. Wu, Z. Q. Zhu, D. Staton, M. Popescu, and D. Hawkins, "Analytical Modeling and Analysis of Open-Circuit Magnet Loss in Surface-Mounted Permanent-Magnet Machines," IEEE Transactions on Magnetics, vol. 48, no. 3, pp. 1234-1247, 2012.

[15] H. Toda, X. Zhenping, W. Jiabin, K. Atallah, and D. Howe, "Rotor eddy-current loss in permanent magnet brushless machines," IEEE Transactions on Magnetics, vol. 40, no. 4, pp. 2104-2106, 2004.

[16] L. J. Wu, Z. Q. Zhu, D. Staton, M. Popescu, and D. Hawkins, "Analytical Model for Predicting Magnet Loss of Surface-Mounted Permanent Magnet Machines Accounting for Slotting Effect and Load," IEEE Transactions on Magnetics, vol. 48, no. 1, pp. 107-117, 2012.

[17] Z. Q. Zhu, K. Ng, N. Schofield, and D. Howe, "Analytical prediction of rotor eddy current loss in brushless machines equipped with surface-mounted permanent magnets. II. Accounting for eddy current reaction field," in Proceedings of the Fifth International Conference on Electrical Machines and Systems, vol.2, pp. 810-813, ICEMS 2001.

[18] D. Fang, "Commutation-caused eddy-current losses in permanent-magnet brushless DC motors," IEEE Transactions on Magnetics, vol. 33, no. 5, pp. 43104318, 1997.

[19] K. Oberretl, "Eddy Current Losses in Solid Pole Shoes of Synchronous Machines at No-Load and on Load," IEEE Transactions on Power Apparatus and Systems, vol. PAS-91, no. 1, pp. 152-160, 1972.

[20] R. Kaczmarek, H. Wan-Ying, and J. C. Vannier, "Magnetic losses simulation in PM SM drive by FE: Harmonic superposition by method of locked rotor," in 9th International Conference on Electrical Power Quality and Utilisation, pp. 1-4, EPQU 2007.

[21] S. A. Sharkh, N. T. Irenji, and M. Harris, "Effect of power factor on rotor loss in high-speed PM alternators," in Ninth International Conference on Electrical Machines and Drives, 1999. , pp. 346-350.

[22] H. Yunkai, D. Jianning, J. Long, Z. Jianguo, and G. Youguang, "Eddy-Current Loss Prediction in the Rotor Magnets of a Permanent Magnet Synchronous Generator With Modular Winding Feeding a Rectifier Load," IEEE Transactions on Magnetics, vol. 47, no. 10, pp. 4203-4206, 2011.

[23] D. Zarko, D. Ban, and T. A. Lipo, "Analytical calculation of magnetic field distribution in the slotted air gap of a surface permanent-magnet motor using complex relative air-gap permeance," IEEE Transactions on Magnetics, vol. 42, no. 7, pp. 18281837, 2006.
[24] Z. Q. Zhu, D. Howe, and C. C. Chan, "Improved analytical model for predicting the magnetic field distribution in brushless permanent-magnet machines," IEEE Transactions on Magnetics, vol. 38, no. 1, pp. 229-238, 2002.

[25] G. McPherson, "An Introduction to Electical Machines and Transformers ", 1981

[26] A. PL, "The nature of induction machines," Gordon and Breach, Science Publishers Inc., London, 1965. 